DOI 10.37882/2500-3682.2020.05.17

\title{
ОСОБЕННОСТИ ПСИХОЛОГИЧЕСКОЙ АДАПТАЦИИ СТУДЕНТОВ К ОБРАЗОВАТЕЛЬНОЙ СРЕДЕ КАРЬЕРНОГО ТИПА
}

\section{FEATURES OF PSYCHOLOGICAL ADAPTATION OF STUDENTS TO THE EDUCATIONAL ENVIRONMENT OF A CAREER TYPE}

N. Tkachenko

Summary: The data presented in the article expands theoretical ideas about the features of adaptation of students to the career environment of higher professional education, clarify ideas about the academic and sociopsychological resources of adaptation to the educational environment. The article shows that the adaptation of students to the educational environment of a higher educational institution includes a whole range of self-changes and the development of new personal qualities. It was revealed that adaptation to the career environment of dependent activity is not productive for the further development of the professional, determining the development of dependence and infantilism. In the process of an individual's adaptation to this educational environment, a transformation occurs both in the cognitive and socio-psychological sphere of the personality. The peculiarity of students' adaptation to the career environment of active dependence is its higher and harmonious nature, but at the same time the educational environment itself is outdated and not able to sufficiently satisfy the needs of students.

Keywords: educational environment, career environment, activity, passivity, freedom, dependence, academic and socio-psychological adaptation.
Ткаченко Наталия Николаевна

заместитель директора колледжа физической культуры,

Воронежский государственный

институт физической культуры

natali.tkachenko.1968@mail.ru

Аннотация: В статье рассматриваются результаты исследования социальнопсихологической адаптации к особенностям карьерной образовательной среды. Представлен теоретический анализ представлений 06 особенностях адаптации студентов к карьерной среде высшего профессионального образования, уточняют представления об академическом и социально-психологическом ресурсе адаптации к образовательной среде. В статье показано, что адаптация студентов к образовательной среде высшего учебного заведения включает в себя целый спектр личностных самоизменений обучающихся и выработку у них новых личностных качеств. Выявлено, что адаптация к карьерной среде зависимой активности не является продуктивной для дальнейшего развития профессионала, детерминируя развитие зависимости и инфантилизма. В процессе адаптации личности к данной образовательной среде происходит трансформация как когнитивной, так и социально-психологической сферы личности. Особенностью адаптации студентов к карьерной среде активной зависимости является ее более высокий и гармоничный характер, а также неспособность в достаточной степени удовлетворить потребности студентов. Результаты представление в статье носят практико-ориентированный характер, так как могут использоваться в работе педагогов, кураторов и служб психолого-педагогического сопровождения студентов для решения и предупреждения проблем адаптации студентов в разных типах образовательных сред.

Ключевые слова: образовательная среда, карьерная среда, активность, пассивность, свобода, зависимость, академическая и социально-психологическая адаптация.

ности к адаптации, как одного из ведущих качеств личности. Как показал проведенный нами теоретический анализ психолого-педагогической литературы, по сей день наблюдается отсутствие единой теории которая бы раскрыла сущность адаптационного процесса в общем, и адаптации к образовательной среде высшего учебного заведения, в частности. Очевидно одно, успешная, эффективная, оптимальная адаптация студентов к образовательной среде выступает гарантом дальнейшего развития каждого обучающегося как человека, гражданина, будущего специалиста.

Адаптация к образовательной среде высшего учебного заведения рассматривается нами как многоуровневый социально-психофизиологический процесс, заключающийся в формировании и приспособлении определенных свойств личности (включая профессионально важные качества) к комплексной системе педагогических, психологических и организационных условий и воздей- 
ствий, обеспечивающих когнитивное, эмоциональное, коммуникативное и, в целом, субъектно-личностное развитие студентов на основе их природных и возрастных особенностей с учетом целей общества и характера развития многоэтапной и многокомпонентной системы высшего образования.

Актуальность изучения проблемы адаптации студентов к разным типам образовательных сред продиктована противоречиями:

- между востребованностью в современном российском обществе высококвалифицированных специалистов с высоким уровнем готовности к дальнейшей профессиональной деятельности, и отсутствием научных данных об особенностях адаптации студентов к разнообразным образовательным средам осуществляющим профессиональную подготовку будущих специалистов;

- между необходимостью в адаптации студентов к образовательному учреждению и недостаточной теоретической и методической разработанностью в педагогической практике данной проблемы в области высшего профессионального образования.

Цель данного исследования - выявить особенности адаптации студентов к карьерной образовательной среде разного типа.

Для решения поставленных задач и проверки выдвинутых гипотез были использованы следующие методы исследования: теоретико-методологический анализ литературных источников по теме, психодиагностические методы: моделирование, экспертиза [1], опрос, психологические тесты-опросники, корреляционный анализ.

В исследовании принимали участие студенты, обучающиеся в классическом и техническом высшем учебном заведении. Общее количество опрошенных составило 283 студента.

Результаты моделирования и экспертизы исследуемых образовательных сред ранее подробно нами описаны [2], в данной работе считаем возможным сразу перейти к рассмотрению особенностей психологической адаптации студентов к карьерной образовательной среде. Начнем с карьерной среды зависимой активности (табл.1).

Данные, представленные в таблице, свидетельствуют о том, что студенты недостаточно используют социальнопсихологические и академические резервы в целях адаптации к образовательной среде. Более развитой является система адаптации студентов к деятельности направленной на изменение образовательной среды. Учитывая, что в данной группе нами обнаружен самый невысокий уровень эмоционального отношения к образовательному учреждению можно предположить, что студенты с помощью личностных качеств (стремления к лидерству, локус-контроля, организованности) стремятся внести изменения и усовершенствовать образовательный процесс. Скорее всего, это свидетельствует не столько об активности студентов, сколько о дискомфортных условиях созданных в образовательной среде и стремлении их разрушить [1].

Таблица №1

Адаптация студентов к карьерной среде зависимой активности

\begin{tabular}{|c|c|c|c|c|c|c|c|}
\hline \multirow[t]{2}{*}{ Показатели } & \multicolumn{5}{|c|}{ Отношение к образовательной среде } & \multicolumn{2}{|c|}{ Сис.коор. } \\
\hline & Эмоц. & Позн. & Практ. & Поступ. & Инт.отн. & Своб.-зав. & Акт.- пас. \\
\hline Потребностно-мотивационная сфера & 0,07 & $\underline{0,21}$ & 0,15 & $-0,06$ & 0,16 & $\underline{-0,23}$ & 0,12 \\
\hline Эмоциональная сфера & 0,14 & 0,04 & 0,15 & $\underline{0,18}$ & $\underline{0,22}$ & 0,10 & $-0,03$ \\
\hline Когнитивная сфера & $\underline{-0,18}$ & 0,21 & $\underline{0,27}$ & 0,11 & $\underline{0,23}$ & $-0,11$ & 0,13 \\
\hline Социально-психологическая сфера & 0,08 & 0,05 & 0,03 & 0,06 & 0,08 & 0,01 & 0,16 \\
\hline Организационные составляющие & $\underline{0,25}$ & $-0,02$ & $-0,03$ & $-0,01$ & 0,05 & 0,11 & 0,02 \\
\hline Адаптация & $-0,14$ & 0,09 & $\underline{0,18}$ & 0,00 & 0,09 & $\underline{-0,20}$ & $\underline{0,18}$ \\
\hline Самопринятие & 0,00 & $-0,06$ & 0,09 & $-0,05$ & 0,01 & $\underline{-0,26}$ & 0,16 \\
\hline Принятие других & 0,03 & 0,06 & 0,09 & 0,02 & 0,09 & $-0,13$ & $\underline{0,17}$ \\
\hline Экстернальность & $-0,16$ & 0,09 & $\underline{0,18}$ & 0,08 & 0,13 & $\underline{-0,30}$ & 0,11 \\
\hline Интернальность & $\underline{-0,17}$ & $\underline{0,24}$ & $\underline{0,27}$ & 0,11 & $\underline{0,24}$ & $-0,12$ & $\underline{0,17}$ \\
\hline Стремление доминировать & $\underline{-0,20}$ & 0,02 & $\underline{0,21}$ & $-0,01$ & 0,06 & $-0,06$ & $-0,02$ \\
\hline Любознательность & $-0,04$ & 0,01 & 0,02 & $-0,14$ & $-0,06$ & $-0,13$ & $-0,01$ \\
\hline Организованность & $-0,27$ & 0,14 & $\underline{0,30}$ & 0,01 & 0,15 & 0,05 & 0,01 \\
\hline Активность & 0,07 & 0,16 & 0,06 & $-0,08$ & 0,08 & $\underline{-0,26}$ & 0,05 \\
\hline$\%$ & $12 \%$ & $14 \%$ & $42 \%$ & $7 \%$ & $21 \%$ & $35 \%$ & $21 \%$ \\
\hline
\end{tabular}


Интересные данные мы получили по вектору «свобода-зависимость». Так когнитивная сфера студентов, уровень их самопринятия и принятия других взаимосвязаны с адаптацией к зависимости образовательной среды. С одной стороны, сформированные академические и социально-психологические резервы действительно выступают основой адаптации к образовательной среде, но с другой необходимо помнить, что любая зависимость - это ограничение степеней свободы, а стержнем зависимой личности является инфантилизм [3].

Опираясь на идеи И.Н. Пятницкой, которая выделила характеристики личности склонной к зависимости, акцентируем внимание на том, что во время адаптации студентов к образовательной среде зависимости активной они становятся более равнодушными к социальным проблемам, у их отсутствует устойчивые и сформированные индивидуальные интересы [4]. В перспективе формирование в такой образовательной среде может детерминировать обособление личности от других, повышение уровня агрессивности к обществу и поиск чувственных впечатлений. Что, очевидно, не является продуктивным в плане формирования будущего специалиста.

В процессе адаптации к карьерной среде зависимой активности у студентов также формируются патологически изменённые потребности, нарушается иерархия мотивов, что, в перспективе, учитывая достаточно высокий уровень активности может быть причиной их неуправляемости [5].
Сформированная в данной образовательной среде личность отличается неспособностью адекватно планировать и прогнозировать своё будущее, что также является непродуктивным в плане дальнейшей адаптации к профессиональной деятельности.

Таким образом адаптация к карьерной среде зависимой активности не является продуктивной для дальнейшего развития профессионала, детерминируя развитие зависимости и инфантилизма. В процессе адаптации личности к данной образовательной среде происходит трансформация как когнитивной, так и социально-психологической сферы личности. У субъектов карьерной образовательной среды невозможной становится свободная линия поведения, их отличает неспособность адекватно планировать и прогнозировать свое будущее.

Далее рассмотрим особенности адаптации студентов к карьерной среде активной зависимости (табл.2).

Представленные в таблице данные свидетельствуют о том, что социально-психологические и академические ресурсы способствую адаптации студентов к образовательной среде, а сам процесс адаптации происходит гармонично и соразмерно по отношению к разным параметрам карьерной среды активной зависимости.

Отличительной особенностью адаптации студентов к карьерной образовательной среде активной зависимости является снижение адаптации при развитии социально-психологической сферы. С одной стороны, данный ре-

Таблица №2

Адаптация студентов к карьерной среде активной зависимости

\begin{tabular}{|c|c|c|c|c|c|c|c|}
\hline \multirow[t]{2}{*}{ Показатели } & \multicolumn{5}{|c|}{ Отношение к образовательной среде } & \multicolumn{2}{|c|}{ Сис.коор. } \\
\hline & Эмоц. & Позн. & Практ. & Поступ. & Инт.отн. & Своб.-зав. & Акт.- пас. \\
\hline Потребностно-мотивационная сфера & $\underline{0,34}$ & $\underline{0,24}$ & $\underline{0,43}$ & $\underline{0,19}$ & $\underline{0,35}$ & $\underline{0,35}$ & $\underline{0,23}$ \\
\hline Эмоциональная сфера & 0,00 & $-0,15$ & $\underline{0,42}$ & $-0,11$ & 0,03 & $\underline{-0,30}$ & 0,05 \\
\hline Когнитивная сфера & $\underline{0,24}$ & $\underline{0,25}$ & $\underline{0,69}$ & 0,27 & 0,44 & $\underline{0,34}$ & $\underline{0,20}$ \\
\hline Социально-психологическая сфера & $-0,23$ & $\underline{-0,47}$ & 0,04 & $\underline{-0,53}$ & $\underline{-0,42}$ & $-0,15$ & $\underline{0,31}$ \\
\hline Организационные составляющие & 0,17 & $\underline{0,18}$ & $\underline{0,55}$ & $\underline{0,19}$ & $\underline{0,33}$ & $-0,05$ & $\underline{0,24}$ \\
\hline Адаптация & $\underline{0,38}$ & $\underline{0,30}$ & $\underline{0,39}$ & $\underline{0,21}$ & $\underline{0,37}$ & $\underline{0,45}$ & 0,07 \\
\hline Самопринятие & $\underline{0,54}$ & $\underline{0,41}$ & 0,19 & 0,12 & $\underline{0,34}$ & $\underline{0,46}$ & $-0,15$ \\
\hline Принятие других & $\underline{0,54}$ & $\underline{0,36}$ & 0,09 & 0,15 & $\underline{0,31}$ & $\underline{0,87}$ & $\underline{0,21}$ \\
\hline Экстернальность & $\underline{0,46}$ & $\underline{0,39}$ & $\underline{0,42}$ & $\underline{0,35}$ & $\underline{0,49}$ & $\underline{0,29}$ & $\underline{-0,19}$ \\
\hline Интернальность & $\underline{0,49}$ & $\underline{0,26}$ & $\underline{0,44}$ & 0,16 & $\underline{0,37}$ & $\underline{0,35}$ & $-0,05$ \\
\hline Стремление доминировать & $\underline{0,27}$ & 0,00 & $\underline{-0,28}$ & $-0,18$ & $-0,10$ & $\underline{0,63}$ & $\underline{0,19}$ \\
\hline Любознательность & $\underline{0,65}$ & $\underline{0,23}$ & 0,06 & $\underline{-0,21}$ & 0,12 & $\underline{0,33}$ & $\underline{-0,20}$ \\
\hline Организованность & 0,05 & $\underline{0,36}$ & $\underline{0,37}$ & $\underline{0,53}$ & $\underline{0,47}$ & 0,16 & $\underline{0,20}$ \\
\hline Активность & $\underline{0,46}$ & $\underline{0,70}$ & $\underline{0,39}$ & 0,62 & $\underline{0,69}$ & 0,10 & 0,12 \\
\hline$\%$ & $71 \%$ & $85 \%$ & $71 \%$ & $64 \%$ & $64 \%$ & $71 \%$ & 64 \\
\hline
\end{tabular}


зультат несколько противоречив и, на первый взгляд, не поддается логическому объяснению, а с другой вполне очевиден. Социально-психологическую адаптацию студентов, можно рассматривать, как состояние благоприятных взаимоотношений личности и группы. В такой ситуации студенты без длительных внешних и внутренних конфликтов достаточно продуктивно выполняет свою учебную деятельность [6]. Очевидно, что данные особенности взаимоотношений должны способствовать адаптации к образовательной среде. В нашем же исследовании полученные результаты, напротив, свидетельствую том, что развитие описанных характеристик снижает эмоционально-положительное оценивание образовательной среды, деформирует мотивацию и направленность познавательной активности студентов, не способствует формированию готовности студентов осуществлять практическую деятельность, связанную с образовательной средой. Скорее всего это связано с тем, что карьерная среда зависимой активности не способна удовлетворять основные социогенные потребности студентов в полной мере. Очевидно, данная образовательная среда игнорирует ожидания обучающихся в возможности самоутверждения и свободного выражения творческих способностей студентов [7]. В плане дальнейшей адаптации личности к профессиональной деятельности это негативный фактор, так как устаревшие традиции и особенности свойственные образовательной среде не подготавливают молодое поколение к динамичной жизни в современном обществе.

Особенностью адаптации студентов к карьерной среде активной зависимости является ее более высокий и гармоничный характер, но при этом сама образовательная среда является устаревшей и не способной в достаточной степени удовлетворить потребности студентов.

Проведенный анализ позволяет сделать следующие выводы:

Таким образом, адаптация студентов к образовательной среде высшего учебного заведения включает в себя целый спектр самоизменений и выработку новых личностных качеств. Говоря об адаптации студентов к образовательной среде, мы говорим об активном приспособлении личности, об активном самоизменении, самокоррекции в соответствии с теми требованиями, которые предъявляет среда к личности.

В целом адаптация студентов к среде высшего профессионального образования происходит успешно, разнонаправленно и гармонично. В процессе адаптации задействованы и социально-психологические и академические ресурсы личности.

Адаптация к карьерной среде зависимой активности не является продуктивной для дальнейшего развития профессионала, детерминируя развитие зависимости и инфантилизма. В процессе адаптации личности к данной образовательной среде происходит трансформация как когнитивной, так и социально-психологической сферы личности. У субъектов карьерной образовательной среды невозможной становится свободная линия поведения, их отличает неспособность адекватно планировать и прогнозировать свое будущее.

Особенностью адаптации студентов к карьерной среде активной зависимости является ее более высокий и гармоничный характер, но при этом сама образовательная среда является устаревшей и не способной в достаточной степени удовлетворить потребности студентов.

Практическая значимость проведённого исследования заключается в возможности использовать полученные данные в работе педагогов, кураторов и службы психолого-педагогического сопровождения студентов для решения и предупреждения проблем адаптации студентов в разных типах образовательных сред. Материалы, полученные в ходе исследования, могут быть также использованы в разработке адаптационных тренингов, спецкурсов, при организации курса педагогики и психологии высшей школы, в системе повышения квалификации преподавателей вуза.

\section{ЛИТЕРАТУРА}

1. Ясвин В.А. Образовательная среда от моделирования к проектированию. Смысл, Москва, 2001.365 с.

2. Ткаченко Н.Н. Отношение студентов-психологов к образовательной среде вуза // Общество: социология, психология, педагогика. 2018. № 3. С. 49-52.

3. Акопов А.Ю. Свобода от зависимости. Социальные болезни личности. СПб.: - Речь, 2008. - 224 с.

4. Пятницкая И.Н. Подростковая наркология. М.: Медицина, 2002. - 256 с. Два автора, поэтому указываем их в начале описания...

5. Зейгарник Б.В. Патопсихология. - М.: Издательство Московского университета, 1986. - 287 с.

6. Налчаджян А.А. Психологическая адаптация. Механизмы и стратегии. Ереван. - 2010. - 478 c.

7. Денисова А.О. Психологический климат и социально-психологическая адаптация персонала в организации. // Перспективы Науки и 0бразования. 2017. 1 (25) C. 56-59.

() Ткаченко Наталия Николаевна (natali.tkachenko.1968@mail.ru).

Журнал «Современная наука: актуальные проблемы теории и практики» 